\title{
10 \\ Integration of commodity price uncertainty in long-term open pit mine production planning by using an imperialist competitive algorithm
}

\author{
by M. Mokhtarian AsI* and J. Sattarvand ${ }^{\dagger}$
}

\section{Synopsis}

Production planning for an open pit mine is a procedure in which the ore blocks are assigned to different production periods in a way that leads to the highest net present value (NPV) subject to some operational and technical constraints. Incorporation of uncertainty in the input parameters makes this process much more complicated. In this paper we describe a new stochastic optimization procedure, based on the imperialist competitive algorithm (ICA), for long-term production planning of open pit mines under conditions of commodity price or market uncertainty. The procedure involves generating simulated realizations of commodity price values and finding the solution by ICA. The proposed approach has been tested on a real-world copper mine and the results show that ICA could be efficiently applied to stochastic production planning of a real mine.

Keywords imperialist competitive algorithm, stochastic programming, open pit mining, production planning, commodity price uncertainty.

\section{Introduction}

Production planning for open pit mines is a complex and significant problem that has been investigated by many researchers. The planning process usually starts with the construction of a geological block model, which comprises the set of imaginary regular blocks that covers the ore deposit and surrounding host rock. A set of attributes such as grade, specific gravity, and coordinate is then assigned to or estimated for each of these blocks using drill-hole sample data. Geological attributes are combined with technical and economic parameters in the next stage to determine the monetary value of each block and construct the economic block model, which provides the basic input for the production planning problem.

Generally, production planning for an open pit mine entails finding the sequence of blocks for the optimal annual schedules in a way that leads to the highest net present value (NPV) of the project cash flows, while meeting the technical constraints such as mining capacity, processing capacity, sequencing, and pit slope (Dagdelen, 2001).

Long-term production planning could be categorized into two major classes, of deterministic and stochastic-based approaches. Deterministic open pit production planning has been studied since 1968 (Johnson, 1968) and, conventionally, several methodologies have been developed, such as integer programming(Caccetta and Hill, 2003; Dagdelen and Johnson, 1986), mixed integer programming (Boland et al., 2009; Elkington and Durham, 2011), dynamic programming (Wang and Sevim, 1992), and meta-heuristic approaches such as the genetic algorithm (Denby and Schofield, 1994), particle swarm algorithm (Khan and Niemann-Delius, 2014), and ant colony algorithm (Sattarvand and Niemann-Delius, 2009; Shishvan and Sattarvand, 2015). The fundamental and significant drawback of these approaches is the assumptions about input parameters. Assuming exactly known (deterministic) parameters, unlike reality in which a significant degree of uncertainty is associated with these parameters, may lead to unrealistic and incorrect production planning (Abdel Sabour and Poulin, 2010; Dimitrakopoulos, Farrelly, and Godoy, 2002; Marcotte and Caron, 2013).

Unlike the conventional deterministic mine design process, which is usually implemented based on deterministic input parameters, stochastic planning of open pit mines considers uncertainty in input parameters. This approach has attracted research during the last decade and several methods have been developed, which can be divided into three main categories: mathematical-based, heuristic, and meta-heuristic approaches. Mathematical formulations using linear programming (Dimitrakopoulos, Farrelly, and Godoy, 2002), integer linear programming (Dimitrakopoulos and Ramazan, 2008; Kumral, 2010; Marcotte and Caron, 2013; Moosavi et al., 2014) or maximum flow (Asad

* Faculty of Mining and Metallurgical Engineering, Urmia University of Technology, Urmia, Iran.

+ Department of Mining and Metallurgical Engineering, University of Nevada Reno, Nevada, USA.

(C) The Southern African Institute of Mining and Metallurgy, 2018. ISSN 2225-6253. Paper received Sept. 2016; revised paper received Jan. 2018. 


\section{Integration of commodity price uncertainty in long-term open pit mine production planning}

and Dimitrakopoulos, 2012; Asad, Dimitrakopoulos, and van Eldert, 2014; Chatterjee et al., 2016) have been developed to solve stochastic problems. The maximum upside potential / minimum downside risk method (Dimitrakopoulos, Martinez, and Ramazan, 2007) is predominant among the heuristic techniques. Genetic algorithms (Denby and Schofield, 1995), simulated annealing (Albor Consuegra and Dimitrakopoulos, 2009), Tabu search (Lamghari and Dimitrakopoulos, 2012), and ant colony algorithm (Gilani and Sattarvand, 2016) meta-heuristic approaches have also been reported to be successfully applied. The majority of research has been focused on incorporation of metal grade uncertainty. Investigation into commodity price uncertainty seems to be in need of further development.

In this paper we propose an efficient solution methodology based on the imperialist competitive algorithm (ICA) to solve real-scale planning problems that are present due to commodity price uncertainty. The procedure has the capability to simultaneously optimize the ultimate pit limit (UPL) and production scheduling.

\section{Commodity price simulation}

A review of price fluctuations of raw minerals shows that the prices of mining products are highly volatile. For example, as illustrated in Figure 1, the price of copper has been highly volatile during the past 30 years (Indexmundi, 2018), with variations of approximately 200\% from 2004 to 2011. Commodity price uncertainty clearly plays an important role in production planning, as constant-price-based planning would lead to an unrealistic answer, increasing the investment risk and the risk due to economic downturns.

Uncertainty in metal prices in future arises because of two main factors:

1. The lack of exact knowledge of factors leading to the increase/decrease in metal supply and demand

2. The practices of producers or consumers in the face of powerful speculative and political motives (Macavoy, 1988).

Forecasting is the process of making statements about events whose actual outcomes have not yet been observed. It is the prediction of future events and is often based on past experiences. The accuracy of predictions of input assumptions is a key factor for success of the procedure.

Several forecasting approaches have been developed to date that could be utilized to simulate future price

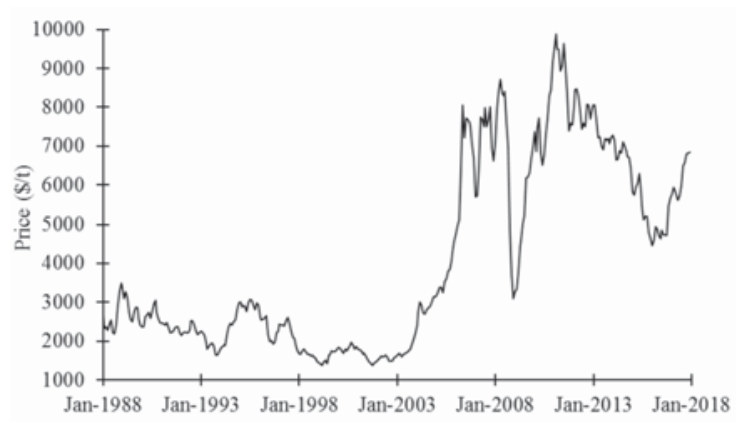

Figure 1-Fluctuation in the copper price during last 30 years (Indexmundi, 2018) fluctuations. Using stochastic processes is a popular commodity price forecasting method. A stochastic process changes a variable over time in a random way, such as in a Wiener process. A Wiener process is a continuous-time stochastic process with three important properties. Firstly, it is a Markov process. This means that the probability distribution of all future values of the process depends only on its current value and is unaffected by past values of the process or by any other current information. Secondly, a Wiener process has independent increments. This means that the probability distribution for the change in the process over any time interval is independent of any other time interval. Finally, changes in the process over any finite interval of time are normally distributed, with a variance that increases linearly with the time interval. The most commonly used stochastic processes are the geometric Brownian motion (GBM) and the mean reverting process (MRP) (Dixit and Pindyck, 1994). Generally, the MRP is appropriate for modelling variables that have a long-term equilibrium level, such as metal prices (Schwartz, 1997). The logic behind a MRP derives from microeconomics: when prices are depressed (or below their long-term mean level), the demand for the product tends to increase while production tends to decrease. The opposite will occur if prices are high (or above the long-term mean) (Pindyck and Rubinfeld, 1998). The simplest form of MRP is the one-factor Ornstein-Uhlenbeck process, which is defined by:

$$
d x_{t}=\eta\left(\bar{x}-x_{t}\right) d t+\sigma d z_{t}
$$

where $x_{t}$ is the variable, $\eta$ the mean reversion speed, $\bar{x}$ is the long-term average to which $x_{t}$ reverts, $\sigma$ the volatility of process, and $d z_{t}$ is the standard Wiener process (Dixit and Pindyck, 1994). The natural logarithm of the variable is used since in the case of commodities it is generally assumed that these prices have a lognormal distribution. Under this condition, Schwartz (1997) proposed the commodity price $(S)$ follows the mean reversion process, as:

$$
d S=\eta[\ln \bar{S}-\ln S] S \cdot d t+\sigma \cdot S \cdot d z
$$

where $\bar{S}$ is the long-term mean price.

\section{Formulation of mine production planning under uncertainty}

The uncertainties in input parameters could be divided into those that arise from the nature of the variables and those that are too expensive to be defined. For example, metal grade of the orebody is a variable whose uncertainty would be diminished by extension of the exploratory studies, which requires time and money (Abdel Sabour, Dimitrakopoulos, and Kumral, 2008). In contrast, commodity price is a variable where uncertainty arises from a number of factors and exact forecasting is not possible for future years. From an economic point of view, uncertain future commodity prices have a critical influence on mine project evaluation (Asad and Dimitrakopoulos, 2013; Haque, Topal, and Lilford, 2014).

Open pit production planning under commodity price uncertainty may be effectively modelled as a stochastic integer programming (SIP) formulation with the objective of NPV maximization subject to a set of technical and operational constrains. It can be expressed as follows: 


\section{Integration of commodity price uncertainty in long-term open pit mine production planning}

$$
\text { Maximize } \sum_{r=1}^{R} p_{r} \sum_{t=1}^{T} \sum_{n=1}^{N} \frac{v_{r m}}{(1+d)^{t-1}} x_{t}
$$

where:

$T: \quad$ Number of time periods

$N$ : Number of mine blocks

$R \quad$ total number of price realizations for each year of the mine life

$p_{r}:$ Probability of realization $r$

$v_{r t n}$ : Economic value of a block $n$ in period $t$ and realization $r$

$x_{t n}$ : Binary decision variables of the model $\left(x_{t n}=1\right.$ if block $n$

is mined in time period $t$, otherwise $x_{t n}=0$ )

$d$ : Annual discount rate.

The economic value of a block equals the difference between revenue earned from selling the commodity (mineral) content of that block and the total costs involved in its mining and processing. For example, for a copper mine, the economic value of block $\mathrm{n}$ is calculated as follows:

$$
\begin{aligned}
& \text { Retum }_{m}=\left(\begin{array}{l}
{\left[\left(\text { Copper price }_{t}-\text { Sales costs }\right) \times \text { Recovery } \times \text { Tonnage }_{n} \times \text { grade }_{n}\right]} \\
-[(\text { Mining cost }+ \text { Milling cost }+ \text { Smelting cost } \\
+ \text { Refining cost }+ \text { Trunsport cost })]
\end{array}\right) \\
& v_{m}=\max \left[\text { Return }_{m},\left(-{\text { Mining } \left.\cos t_{m}\right)}\right)\right]
\end{aligned}
$$

The described objective function is subject to the following constraints.

Mining capacity constraints: Total tonnage of extracted material should be between a pre-determined upper and lower limit for each scheduling period.

$$
M C_{\text {min }}^{t} \leq \sum_{n=1}^{N} W_{n} \cdot x_{t n} \leq M C_{\max }^{t} \text { for } \forall t
$$

where

$W_{n}$ : Tonnage of block $n$

$M C_{\text {max }}^{t}, M C_{\text {min }}^{t}$ : Maximum and minimum acceptable mining capacity for period $t$.

Processing capacity constraints: Quantity of ore production should satisfy processing capacity limitations:

$$
P C_{m i n}^{t} \leq \sum_{n=1}^{N} O_{m} x_{t m} \leq P C_{\max }^{t} \text { for } \forall t \text { and } \forall r
$$

where

$O_{r n}$ : Tonnage of ore block $n$ in realization $r$. If the block economic value is greater than zero $\left(v_{n}>0\right)$, it will be considered as ore

$P C_{\max }^{t}, P C_{\min }^{t}$ : Maximum and minimum tolerable processing capacity for period $t$.

Reserve constraint: This constraint is mathematically necessary to ensure that a block is mined only once in the model.

$$
\sum_{t=1}^{T} x_{t m} \leq 1 \text { for } \forall n
$$

Sequencing constraints: The sequencing constraints ensure that a block can be removed only if all overlying blocks have been removed earlier periods or are considered for the same period, $t$.

$$
\sum_{i=1}^{t}\left(x_{l j}-x_{t i}\right) \geq 0, \quad t=1, \ldots, T, \text { for } \forall(i, j) \in A
$$

where $A$ is the set of pairs $(i, j)$ of blocks such that block $j$ is a key block to block $i$ and must be removed before block $i$ can be mined.

The fundamental and significant drawback of this approach is the high computational cost when applied to realworld problems. In most cases, the block model contains thousands to millions of blocks that make up a SIP model with millions of integer variables and constraints, which can be extremely difficult or expensive to solve. Investigation using a higher class of heuristics, called meta-heuristics, has been of interest recently. A meta-heuristic is a set of algorithmic concepts that can enhance the applicability of heuristic methods to difficult problems. These concepts are usually inspired by biology and nature. The use of metaheuristic methods has significantly increased the ability to find very high-quality solutions for hard combinatorial problems in a reasonable computation time (Dorigo, Birattari, and Stützle, 2006).

\section{Imperialist competitive algorithm (ICA)}

Imperialism is the strategy of expanding the power and scope of rule of government beyond its own boundaries through any type of domination, such as direct rule or by less obvious instruments such as cultural influence, market control, or control of energy and other important commodities. The imperialist competitive algorithm (ICA) is a novel populationbased meta-heuristic algorithm proposed by AtashpazGargari and Lucas (2007), mimicking the socio-political process of imperialism and imperialistic competition as a source of inspiration (Khabbazi, Atashpaz-Gargari, and Lucas, 2009). The algorithm's capability in dealing with different types of optimization problems has been proven by the authors (Atashpaz-Gargari and Lucas, 2007). Similar to any evolutionary algorithm, ICA also starts with an initial population of solutions, called countries, representing the concept of nations. Based on the quality of the objective function in each solution, some of the best countries in the population are chosen to be the 'imperialists' and the rest are assumed to be the 'colonies' of those imperialists. A set of one imperialist and its colonies is called an 'empire' (Shokrollahpour, Zandieh, and Dorri, 2011). Over time, imperialists try to extend their own characteristics to the governing colonies; however, it is not a tightly controlled procedure and 'revolutions' may happen in each country. Countries can also leave an empire and migrate to another if they see a better chance of promotion there. Within each empire the position of imperialist could be altered too. Iteratively, the algorithm evolves towards better countries and empires. ICA has been used extensively to solve different kinds of optimization problems. For example, this method is used for stock market forecasting (Sadaei et al., 2016), digital filter design (Sharifi and Mojallali, 2015), travelling salesman problems (Ardalan et al., 2015), multi-objective optimization (Maroufmashat, Sayedin, and Khavas, 2014), integrated product mix-outsourcing problems (NazariShirkouhi et al., 2010), and scheduling problems (Behnamian and Zandieh, 2011, Lian et al., 2012).

The following sections describe the practical implementation of ICA in open pit mine production planning. The flow chart of the proposed procedure is illustrated in Figure 2. 


\section{Integration of commodity price uncertainty in long-term open pit mine production planning}

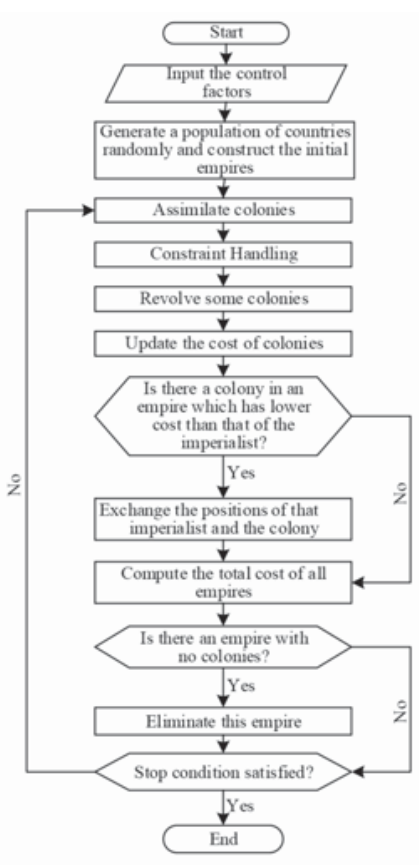

Figure 2-Flow chart of imperialist competitive algorithm

\section{Generating initial empires}

The main purpose of optimization is to find an optimal solution; each solution in this algorithm is called a 'country'. In an $n$-dimensional optimization problem, a country is an $n \times 1$ array as follow:

$$
\text { country }=\left[p_{1}, p_{2}, p_{3}, \ldots, p_{n}\right]
$$

where $p_{i}$ s are decision variables whose values need to be determined in order to maximize or minimize the objective function. The decision variables of an open pit mine production planning problem are the extraction time of the blocks in the economic block model, and the objective is to maximize the NPV of the project.

To start the optimization algorithm, an initial population is generated containing $N_{p o p}$ solutions (mine schedules), among which $N_{i m p}$ of the most powerful solutions (according to their NPVs) are selected as 'imperialists'. The rest of the population members $\left(N_{c o l}=N_{p o p}-N_{i m p}\right)$ will be the colonies of the chosen empires. To form the primary empires, colonies are randomly divided among the imperialists based on their power as the higher the power of an empire, the more colonies belong it. To proportionally distribute the colonies among imperialists, the normalized cost of the $n^{\text {th }}$ imperialist is defined as:

$$
C_{n}=\max \left\{c_{i}\right\}-c_{n}, \quad i=1,2, \ldots, N_{i m p}
$$

where $c_{n}$ and $C_{n}$ are the cost and the normalized cost of $n^{\text {th }}$ imperialist respectively. The objective of ICA is set to minimize the sum of the cost function value of all countries.

To convert the production planning problem from maximization to minimization, the negative value of the NPV is used as the cost function.

$$
\operatorname{Cost}(\text { country })=-\sum_{r=1}^{R} p_{r} \sum_{t=1}^{T} \sum_{n=1}^{N} \frac{v_{r m}}{(1+d)^{t-1}} x_{t n}
$$

Hence the normalized power of each imperialist can be determined as below:

$$
\text { pow }_{n}=\left|C_{n} / \sum_{i=1}^{N_{\text {inp }}} C_{i}\right|
$$

The normalized power of an imperialist indicates the number of colonies that should be probably controlled by that imperialist. Thus, the initial number of colonies of an empire will be as follows:

$$
\operatorname{ColEmp}_{n}=\operatorname{round}\left(\text { pow }_{n} \times N_{\text {col }}\right)
$$

where ColEmp $p_{n}$ is the initial number of the colonies of the $n^{\text {th }}$ empire; those are chosen randomly from the whole colony population. Each imperialist together with its colonies will form an empire.

\section{Modified assimilation process}

The goal of an assimilation policy is to improve the properties of the colonies. This policy is implemented by moving all the colonies toward their corresponding imperialist. The colonies will approach the imperialist along different socio-political axes such as culture, language, etc. As shown in Figure 3, the assimilating operator for the open pit mine production planning problem follows the steps below:

> Create the country array with the size equal to the number of blocks in the block model of the mine. The value of the cell $n$ in array is equal to unity if block $n$ is mined (the coloured blocks in Figure 3), and equal to zero otherwise

> Select a sub-array randomly in the imperialist array (for example, cells 5 to 11)

> Copy the imperialist sub-array to the colony array.

\section{Constraint handling}

There is not an explicit mechanism for constraint handling in ICA. Considering the special structure of constraints involved in the production scheduling of an open pit mine, the following two constraint handling techniques may be used.

\section{Sequencing constraint}

Usually, the assimilated colony (Figure 3) does not result in a feasible pit shape with acceptable slope angles and block precedency. A feasible pit generation procedure is called
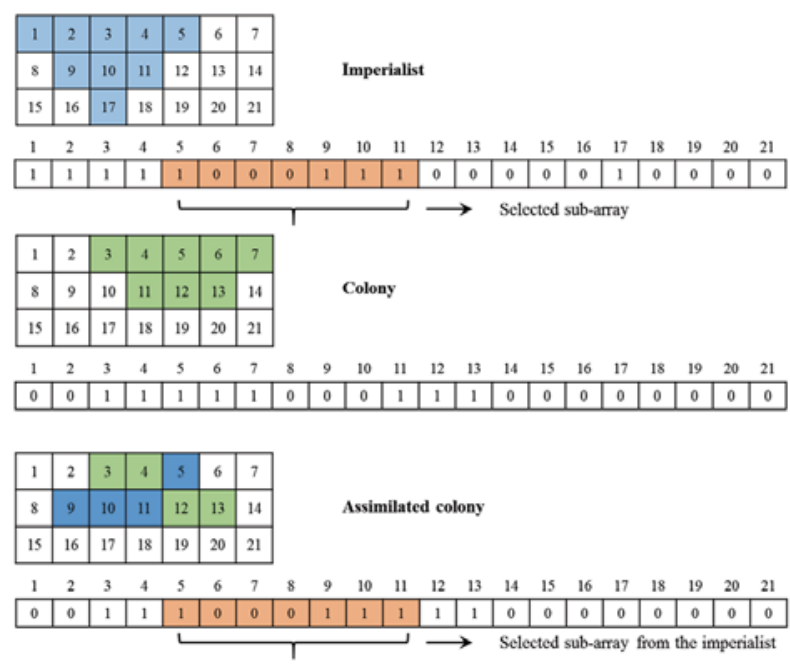

Figure 3-Assimilation operator for a production planning problem 


\section{Integration of commodity price uncertainty in long-term open pit mine production planning}

normalization. Consequently, normalization is required to satisfy any sequencing constraints (Equation [9]), as shown in Figure 4.

\section{Capacity constraint}

To deal with violations of mining and processing capacity constraints a constant penalty method has been used. The objective function (Equation [5]) can be written as follows:

$$
\begin{gathered}
\text { Maximize } \sum_{r=1}^{R} p_{r} \sum_{t=1}^{T} \sum_{n=1}^{N} \frac{v_{r t m}}{(1+d)^{t-1}} x_{t n}- \\
P_{t}^{M-} M_{r t}^{-}-P_{t}^{M+} M_{r t}^{+}-P_{t}^{O-} O_{r t}^{-}-P_{t}^{O+} O_{r t}^{+}
\end{gathered}
$$

where

$P_{t}^{M-}, P_{t}^{M+}$ : Represent the discounted unit costs (penalty) for a shortage or surplus in the total weight of rock mined in period $t$, respectively

$M_{\bar{r}}, M_{r t}^{+}$: Denote the shortage or surplus in the amount of rock mined during period $t$ if scenario $r$ occurs, respectively

$P_{t}^{O_{-}}, P_{t}^{O_{+}}$: Represent the discounted unit costs (penalty) for a shortage or surplus in the ore produced in period $t$, respectively

$O_{r t}, O_{r t}^{+}: \quad$ Represent the shortage or excess amount of ore produced in period $t$ if scenario $r$ occurs, respectively.

\section{Revolution}

While the assimilation process is responsible for intensification, a revolution mechanism diversifies ICA to explore new regions. The revolution mechanism prevents the algorithm from being trapped in local optima. It is only applied to colonies, and imperialists remain untouched (Mortazavi, Khamseh, and Naderi, 2015). For this purpose, the weakest colony (production plans with the lowest NPV) in each iteration is selected and replaced with a new one, randomly.

\section{Exchanging positions of the imperialist and a colony}

When moving toward the imperialist, a colony might reach a position with a lower cost function than that of its imperialist. In this condition, the positions of the imperialist and colony are swapped. Afterwards, the algorithm continues using the new imperialist, and colonies move towards the new leader of the empire.
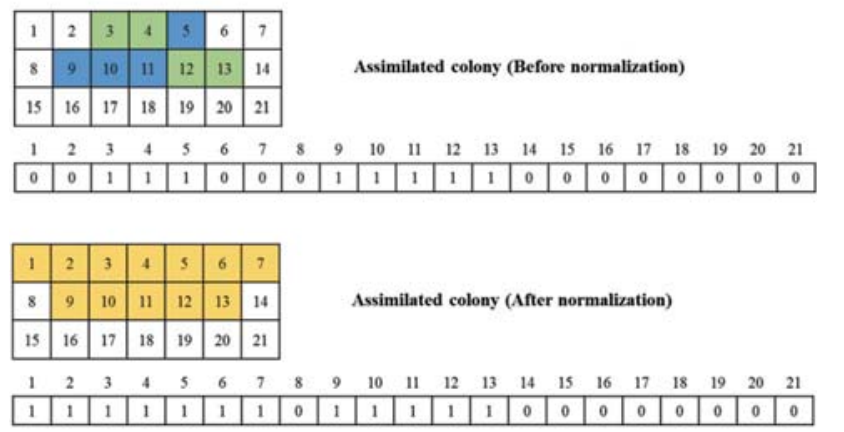

Figure 4-Normalization process for the assimilated colony

\section{Total power of an empire}

The total power of an empire is mainly based on the power of its imperialist country; however, the powers of its individual colonies have also an effect, albeit relatively insignificant. Therefore, the total cost of an empire is described as:

$$
\begin{aligned}
& T C=\operatorname{cost}\left(\text { imperialist }_{n}\right)+ \\
& \xi \text { mean }\left(\operatorname{cost}\left(\text { colonies of empire }_{n}\right)\right)
\end{aligned}
$$

where $T C$ is the total cost of the $n$th empire and $\xi$ is a positive number which is considered to be less than unity. A small value of $\xi$ causes the total power of the empire to be determined by mainly the imperialist, and a larger value will increase the role of the colonies in determining the total power of the empire.

\section{Imperialistic competition}

In general, empires try to take possession of colonies of the other empires and control them. Through this process, the power of weaker empires will decrease and that of the more powerful ones will increase. This competition is modelled by choosing one of the weakest colonies of the weakest empire and creating competition among all empires to possess this colony. Each of the empires (based on its total power) will have a chance to taking ownership of the mentioned colony. In other words, a colony has no certainty of belonging to the most powerful empire; however, the more powerful empires will be more likely to possess it. The possession probability of each empire is proportional to its total power. The normalized total cost of each empire is determined as:

$$
N T C_{n}=\max \left\{T C_{i}\right\}-T C_{n} \quad i=1,2, \ldots, N_{\text {imp }}
$$

where $T C_{n}$ and $N T C_{n}$ are respectively the total cost and normalized total cost of the $n$th empire. Now the possession probability of each empire can be given by:

$$
p_{n}=\left|\frac{N T C_{n}}{\mid \sum_{i=1}^{N_{\text {ing }}} N T C_{i}}\right|
$$

To divide the mentioned colonies among empires based on the possession probability of them, vector $P$, is formed as follows:

$$
P=\left[p_{1}, p_{2}, p_{3}, \ldots, p_{N_{\text {bup }}}\right]
$$

Then, the vector $R$ with the same size as $P$ whose elements are uniformly distributed random numbers between 0 and 1 , is created.

$$
\begin{aligned}
& r=\left[r_{1}, r_{2}, r_{3}, \ldots, r_{\text {imp }}\right], \\
& r_{1}, r_{2}, r_{3}, \ldots, r_{\text {imp }} \sim U(0,1)
\end{aligned}
$$

Then, vector $D$ is formed by subtracting $R$ from $P$.

$$
\begin{aligned}
& D=P-R=\left[d_{1}, d_{2}, d_{3}, \ldots, d_{N_{\mathrm{mmp}}}\right]= \\
& {\left[p_{1}-r_{1}, p_{2}-r_{2}, p_{3}-r_{3}, \ldots, p_{N_{\operatorname{mop}}}-r_{N_{\text {mop }}}\right]}
\end{aligned}
$$

Referring to vector $D$, the mentioned colonies in an empire whose corresponding index in $D$ is maximum will win the possession competition (Atashpaz-Gargari and Lucas, 2007). 


\section{Integration of commodity price uncertainty in long-term open pit mine production planning}

\section{Eliminating powerless empires}

Powerless empires will collapse in imperialistic competition and their colonies will be distributed among other empires. In modelling the collapse mechanism, different factors can be defined to consider an empire as powerless. In the current study, an empire collapses when it loses all of its colonies.

\section{Stopping criteria}

The algorithm continues until no iteration is remaining or just one empire exists in the world.

\section{Numerical results and discussion}

A three-dimensional numerical example was used for examination of the proposed methodology. It consists of a copper deposit with geological block model containing 36720 blocks that are $15 \times 15 \times 15 \mathrm{~m}$ and with a pit slope angle of $45^{\circ}$ along all azimuths. Mining will be operated for 5 years and the maximum and minimum mining capacities are 21.04 and $16.82 \mathrm{Mt} / \mathrm{a}$ respectively. The maximum and minimum processing capacities are considered to be 16.05 and 9.63 $\mathrm{Mt} / \mathrm{a}$ respectively and the discount rate is assumed to be $10 \%$. Table I displays the technical and economic parameters required for the construction of the economic block model. Equation [2] was used for forecasting of future copper price, which was simulated for the next 5 years in 20 realizations (Figure 5). The proposed procedure for applying ICA to a production planning problem in open pit mines has been implemented using the $\mathrm{C}++$ programming language.

The most common performance measure of algorithms that is used in the literature is the relative percentage deviation (RPD). The performance measure for this study has been calculated as follows:

$$
R P D=\frac{M a t h-I C A_{\text {best }}}{I C A_{\text {best }}} \times 100
$$

where $I C A_{b e s t}$ and Math are respectively the best solutions generated by ICA and the optimal mathematical solution.

A hypothetical examination was conducted to test the performance of ICA in an open pit mine production planning

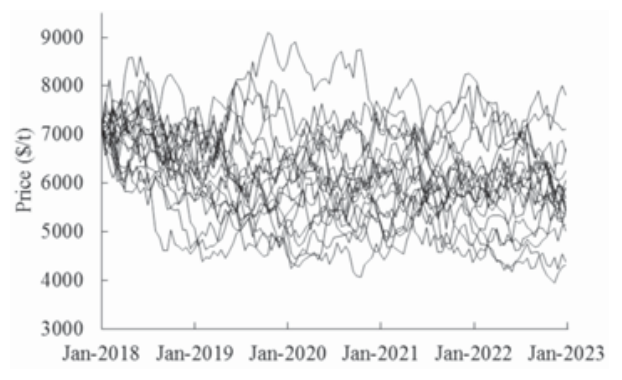

Figure 5-Copper price realizations for the next 5 years

Table I

Technical and economic parameters required for the construction of the economic block model

\begin{tabular}{|l|c|}
\hline Parameter & Value \\
\hline Mill recovery rate & $80 \%$ \\
Mill concentrate grade & $28 \%$ \\
Smelting loss $(\mathrm{kg} / \mathrm{t})$ & 10 \\
Refining loss $(\mathrm{kg} / \mathrm{t})$ & 5 \\
Mining cost $(\$ / \mathrm{t})$ & 1.5 \\
Milling cost $(\$ \mathrm{t})$ & 5.5 \\
General and administration cost $(\$ / \mathrm{t})$ & 0.5 \\
Amortization and depreciation cost $(\$ / \mathrm{t})$ & 0.8 \\
Transport cost of mill concentrate to the smelter $(\$ / \mathrm{t})$ & 30 \\
Smelting cost $(\$ / \mathrm{t})$ & 92 \\
Transport cost of the blister copper to the refinery $(\$ / \mathrm{t})$ & 2 \\
Refining cost $(\$ / \mathrm{t})$ & 184 \\
Selling and delivery cost $(\$ / \mathrm{t})$ & 0.01 \\
General plant cost $(\$ / \mathrm{kg})$ & 0.01 \\
\hline
\end{tabular}

problem. Different levels for various control factors ( $\xi$, number of countries, and number of imperialists) were used in the optimization and are shown in Figure 6. The small RPD show the effectiveness of ICA in mine production planning. Hence, ICA was used for long-term production planning of a real-world copper mine, based on copper price realizations for the next 5 years. Figure 7 shows north-south and east-west sections of the production planning using the ICA approach.

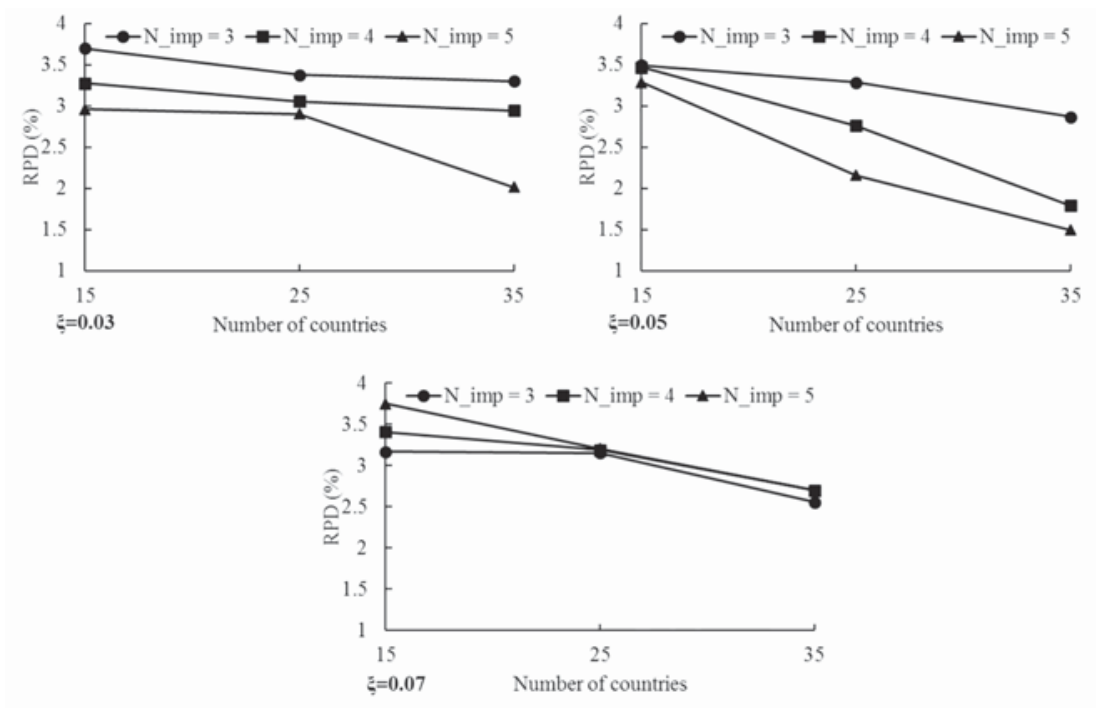

Figure 6-RPD for different values of $\mathrm{N}_{\text {pop }}$ and $\mathrm{N}_{\text {imp }}$ in $\xi=0.03, \xi=0.05$, and $\xi=0.07$ 


\section{Integration of commodity price uncertainty in long-term open pit mine production planning}
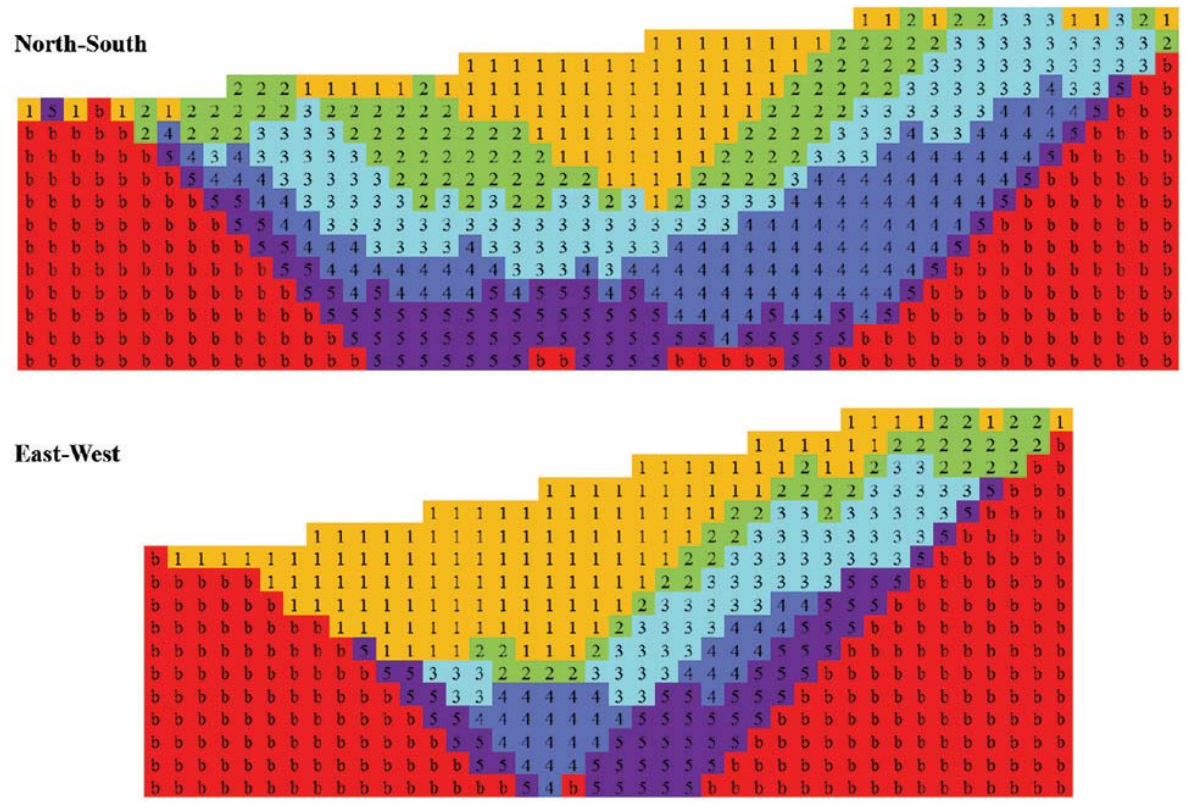

Figure 7-Sections of the copper mine production plan by ICA (the numbers are indicative of block extraction year)

Table II

Comparison of stochastic and conventional approaches

\begin{tabular}{|l|c|c|c|c|c|}
\hline Method & NPV (million \$) & RPD (\%) & Number of blocks inside the UPL & Average grade of UPL (\%) & CPU time (s) \\
\hline ICA & 622.465 & 5.1 & 12205 & 0.304 & 8446 \\
SIP & 654.212 & & 12323 & 0.306 & 19550 \\
\hline
\end{tabular}

In order to compare the new ICA approach with stochastic integer programming methods (SIP), production planning was also performed by SIP. Table II compares the SIP and ICA approaches. It shows the CPU time of the ICA approach equals 8446 seconds, which is less than for the SIP method, and the small RPD shows the effectiveness of ICA in stochastic production planning of a real-world mine. All the numerical experiments were completed on an AMD Athlon (2.01 GHz) and 2.5 GB RAM running Windows 7 .

\section{Conclusion}

Open pit mine production scheduling is difficult as there are a large number of blocks, with the future economic value of the blocks unknown at the time decisions are made. This results in a large-scale stochastic optimization problem. In this work, we proposed a meta-heuristic method based on an imperialist competitive algorithm to solve an important real-world problem that arises in surface mine planning, namely open pit mine production planning with commodity price uncertainty. The approach has been tested on a copper mine. By comparing ICA with the more commonly used stochastic integer programming method, it was shown that the proposed ICA method can produce good quality robust solutions with low RPD and CPU time for mine stochastic production planning.

\section{References}

Abdel Sabour, S.A., Dimitrakopoulos, R.G., and Kumral, M. 2008. Mine design selection under uncertainty. Mining Technology, vol. 117, no. 2. pp. 53-64.

Abdel Sabour, S.A. and Poulin, R. 2010. Mine expansion decisions under uncertainty. International Journal of Mining, Reclamation and Environment, vol. 24, no. 4. pp. 340-349.

Albor Consuegra, F.R. and Dimitrakopoulos, R. 2009. Stochastic mine design optimisation based on simulated annealing: pit limits, production schedules, multiple orebody scenarios and sensitivity analysis. Mining Technology, vol. 118, no. 2. pp. 79-90.

Ardalan, Zaniar, Karimi, Sajad, Poursabzi, Omid, and Naderi, B., 2015, A novel imperialist competitive algorithm for generalized traveling salesman problems. Applied Soft Computing, vol. 26. pp. 546-555.

ASAD, M.W.A. and Dimitrakopoulos, R. 2012, Implementing a parametric maximum flow algorithm for optimal open pit mine design under uncertain supply and demand. Journal of the Operational Research Society, vol. 64, no. 2. pp. 185-197.

Asad, M.W.A., Dimitrakopoulos, R., and van Eldert, J. 2014. Stochastic production phase design for an open pit mining complex with multiple processing streams. Engineering Optimization, vol. 46, no. 8. pp. 1139-1152.

AsAD, M.W.A. and DimitraKopoulos, R. 2013. Implementing a parametric maximum flow algorithm for optimal open pit mine design under uncertain supply and demand. Journal of the Operational Research Society, vol. 64, no. 2. pp. 185-197. 


\section{Integration of commodity price uncertainty in long-term open pit mine production planning}

ATASHPAZ-GARGARI, E. and LuCAS, C. 2007, Imperialist competitive algorithm: an algorithm for optimization inspired by imperialistic competition. Proceedings of the IEEE Congress on Evolutionary Computation (CEC 2007, Singapore, 25-28 September. IEEE, New York.

BEHNAMIAN, J. and ZANDIEH, M, 2011. A discrete colonial competitive algorithm for hybrid flowshop scheduling to minimize earliness and quadratic tardiness penalties. Expert Systems with Applications, vol. 38, no. 12. pp. 14490-14498.

Boland, N., Dumitrescu, I., Froyland, G., and GleiXner, A.M. 2009. LP-based disaggregation approaches to solving the open pit mining production scheduling problem with block processing selectivity. Computers \& Operations Research, vol. 36, no. 4. pp. 1064-1089.

CAcCETTA, L. and HilL, S.P. 2003. An application of branch and cut to open pit mine scheduling. Journal of Global Optimization, vol. 27, no. 2-3. pp. 349-365.

Chatterjee, S., SeThi, M.R., and Asad, M.W.A. 2016. Production phase and ultimate pit limit design under commodity price uncertainty. European Journal of Operational Research, vol. 248, no. 2. pp. 658-667.

DaGDelen, K. 2001. Open pit optimization-strategies for improving economics of mining projects through mine planning. Proceedings of the 17th International Mining Congress and Exhibition of Turkey (IMCET2001), Ankara, Turkey, 19-22 June 2001. Chamber of Mining Engineers of Turkey. https://s3.amazonaws.com/academia.edu.documents/ 30191663/1259a0cb2431834_ek.pdf?AWSAccessKeyId=AKIAIWOWYYG Z2Y53UL3A\&Expires=1519570263\&Signature $=1$ Fys8Kk4TjhehxXNqZsai OE6eNY\%3D\&response-content-disposition=inline\%3B\%20filename\%3D Open_pit_optimization_strategies_for_imp.pdf

Dagdelen, K. and Johnson, T.B. 1986. Optimum open pit mine production scheduling by Lagrangian parameterization. Proceedings of the 19th International Symposium on Application of Computers and Operations Research in the Mineral Industry (APCOM '86). SME, Littleton, CO. pp. 127-142. USA.

DenBy, B. and Schofield, D. 1995. Inclusion of risk assessment in open pit design and scheduling. Transactions of the Institution of Mining and Metallurgy. Section A. Mining Industry, vol. 104. pp. A67-A71.

Denby, B. and Schofield, D. 1994, Open-pit design and scheduling by use of genetic algorithms. Transactions of the Institution of Mining and Metallurgy. Section A. Mining Industry, vol. 103. pp. A21-A26.

Dimitrakopoulos, R., Martinez, L., and Ramazan, S. 2007. A maximum upside / minimum downside approach to the traditional optimization of open pit mine design. Journal of Mining Science, vol. 43, no. 1. pp. 73-82.

Dimitrakopoulos, R. and Ramazan, S. 2008. Stochastic integer programming for optimising long term production schedules of open pit mines: methods, application and value of stochastic solutions. Mining Technology, vol. 117 , no. 4 . pp. $155-160$.

Dimitrakopoulos, R., Farrelly, C., and Godoy, M. 2002. Moving forward from traditional optimization: grade uncertainty and risk effects in open-pit design. Mining Technology, vol. 111, no. 1. pp. 82-88.

Dixit, V.K. and PinDYck, R.S. 1994. Investment under Uncertainty. Princeton University Press

Dorigo, M., Birattari, M., and StÜTZle, T. 2006. Ant colony optimization. Computational Intelligence Magazine, vol. 1, no. 4. pp. 28-39.

ELKington, T. and Durham, R. 2011. Integrated open pit pushback selection and production capacity optimization. Journal of Mining Science, vol. 47, no. 2. pp.177-190.

GiLANI, S-O. and SATTARVAND, J. 2016. Integrating geological uncertainty in long-term open pit mine production planning by ant colony optimization. Computers \& Geosciences, vol. 87. pp. 31-40.

Haque, MD.A., Topal, E., and Lilford, E. 2014, A numerical study for a mining project using real options valuation under commodity price uncertainty. Resource Policy, vol. 39. pp. 115-123.

INDEXMUNDI. 2018. Copper, grade A cathode, LME spot price. World Bank. http://www.indexmundi.com/commodities/?commodity= copper\&months $=300$
JoHnson, T.B.1968. Optimum open-pit mine production scheduling. PhD thesis, Berkeley University.

KHABBAZI, A., AtASHPAZ-Gargari, E., and LuCAS, C. 2009. Imperialist competitive algorithm for minimum bit error rate beamforming, International Journal of Bio-Inspired Computation, vol. 1, no. 1-2. pp. 125-133.

Khan, A. and Niemann-Delius, C. 2014. Production scheduling of open pit mines using particle swarm optimization algorithm. Advances in Operations Research, 2014, no. 1. pp. 1-9.

Kumral, M. 2010. Robust stochastic mine production scheduling. Engineering Optimization, vol. 42, no. 6. pp. 567-579.

LAmghari, A. and Dimitrakopoulos, R. 2012. A diversified Tabu search approach for the open-pit mine production scheduling problem with metal uncertainty. European Journal of Operational Research, vol. 222, no. 3. pp. 642-652.

LiAn, K., ZhAnG, C., GAo, L., and SHAo, X. 2012. A modified colonial competitive algorithm for the mixed-model U-line balancing and sequencing problem, International Journal of Production Research, vol. 50, no. 18. pp. 5117-5131.

Macavoy, P.W. 1988. Explaining metals prices: economic analysis of metals markets in the 1980s and 1990s. Rochester Studies in Managerial Economics and Policy. Brunner, K. (ed.). Kluwer Academic, Boston.

MarcotTE, D. and CARon, J. 2013. Ultimate open pit stochastic optimization. Computers \& Geosciences, vol. 51. pp. 238-246.

Maroufmashat, A., Sayedin, F., and Khavas, S.S. 2014. An imperialist competitive algorithm approach for multi-objective optimization of direct coupling photovoltaic-electrolyzer systems. International Journal of Hydrogen Energy, vol. 39, no. 33. pp. 18743-18757.

Moosavi, E., Gholamnejad, J., Ataee-Pour, M., and Khorram, E. 2014. Improvement of Lagrangian relaxation performance for open pit mines constrained long-term production scheduling problem. Journal of Central South University, vol. 21, no. 7. pp. 2848-2856.

MortazAvi, A., Khamseh, A.A., and NADERI, B. 2015. A novel chaotic imperialist competitive algorithm for production and air transportation scheduling problems. Neural Computing and Applications, vol. 26, no. 7. pp. 1709-1723.

NAZARi-ShiRKouHi, S., EIVAzy, H., GHodsi, R., ReZAiE, K., and AtaShPAZ-Gargari, E. 2010. Solving the integrated product mix-outsourcing problem using the imperialist competitive algorithm. Expert Systems with Applications, vol. 37, no. 12. pp. 7615-7626.

PINDYCK, R.S. and RubinfELD, D.L. 1998. Econometric Models and Economic Forecasts. vol. 4. Irwin/McGraw-Hill, Boston.

Sadaei, H.J., Enayatifar, R., Lee, M.H., and Mahmud, M. 2016, A hybrid model based on differential fuzzy logic relationships and imperialist competitive algorithm for stock market forecasting. Applied Soft Computing, vol. 40. pp. 132-149.

SAtTARvand, J. and Niemann-Delius, C. 2009. Long-term open-pit planning by ant colony optimization. PhD thesis, Institut fur Bergbaukunde III, RWTH Aachen University.

ScHWARTZ, E.S. 1997, The stochastic behavior of commodity prices: Implications for valuation and hedging. Journal of Finance, vol. 52, no. 3. pp. 923-973.

SHARIFI, M.A. AND Mojallali, H. 2015. A modified imperialist competitive algorithm for digital IIR filter design. Optik - International Journal for Light and Electron Optics, vol. 126, no. 21. pp. 2979-2984.

SHISHVAN, M.S. and SATTARVAND, J. 2015. Long term production planning of open pit mines by ant colony optimization. European Journal of Operational Research, vol. 240, no. 3. pp. 825-836.

SHoKrollahpour, E., ZANDIEH, M., and DorRi, B. 2011. A novel imperialist competitive algorithm for bi-criteria scheduling of the assembly flowshop problem. International Journal of Production Research, vol. 49, no. 11. pp. 3087-3103.

WANG, Q. and SEviM, H. 1992. Enhanced production planning in open pit mining through intelligent dynamic search. Proceedings of the $23 \mathrm{rd}$ International Symposium on Application of Computers and Operations Research in the Mineral Industry, Tucson, AZ. Society for Mining, Metallurgy and Exploration, Littleton, CO. pp. 461-471. 